\title{
Chronic hiccup
}

INSERM

\section{Source}

INSERM. (1999). Orphanet: an online rare disease and orphan drug data base. Chronic hiccup. ORPHA:396

Chronic hiccup is a rare movement disorder characterized by involuntary spasmodic contractions of the inspiratory muscles synchronized with larynx closure lasting for more than 48 hours. 